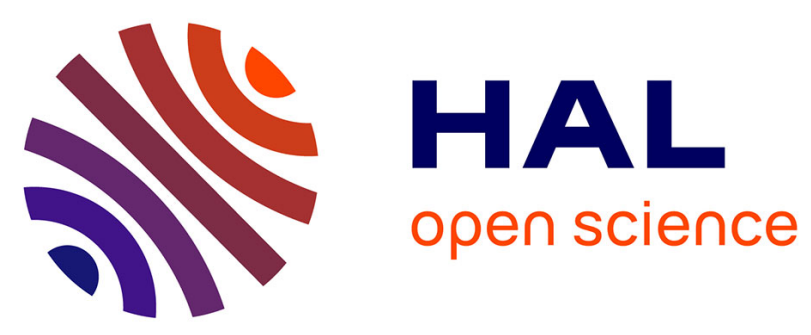

\title{
Kangaroo supported diagonal flexion positioning: Positive impact on maternal stress and postpartum depression risk and on skin-to-skin practice with very preterm infants
}

Aude Buil, Laurence Caeymaex, Sophie Mero, Carol Sankey, Gisèle Apter, Emmanuel Devouche

\section{To cite this version:}

Aude Buil, Laurence Caeymaex, Sophie Mero, Carol Sankey, Gisèle Apter, et al.. Kangaroo supported diagonal flexion positioning: Positive impact on maternal stress and postpartum depression risk and on skin-to-skin practice with very preterm infants. Journal of Neonatal Nursing, 2019, 25, pp.86 - 92. 10.1016/j.jnn.2018.10.006 . hal-03485676

\author{
HAL Id: hal-03485676 \\ https://hal.science/hal-03485676
}

Submitted on 20 Dec 2021

HAL is a multi-disciplinary open access archive for the deposit and dissemination of scientific research documents, whether they are published or not. The documents may come from teaching and research institutions in France or abroad, or from public or private research centers.
L'archive ouverte pluridisciplinaire HAL, est destinée au dépôt et à la diffusion de documents scientifiques de niveau recherche, publiés ou non, émanant des établissements d'enseignement et de recherche français ou étrangers, des laboratoires publics ou privés.

\section{(ㄷ)(1) $\$$}

Distributed under a Creative Commons Attribution - NonCommerciall 4.0 International 
Title page

Kangaroo supported diagonal flexion positioning: positive impact on maternal stress and postpartum depression risk and on skin-to-skin practice with very preterm infants.

Aude Buil

audebuil11@gmail.com

Laurence Caeymaex

laurence.caeymaex@chicreteil.fr

Sophie Mero

sophie.mero@wanadoo.fr

Carol Sankey

csankey@gmail.com

Gisèle Apter

gisele.apter@gmail.com

Emmanuel Devouche

devouche7@gmail.com

\section{Role of the funding source}

This work was supported by three research grants by Fondation Mustela, Fondation pour la Recherche en Psychomotricité et Maladies de Civilisation and Fondation des Treilles. Baby wraps were provided by L'école à porter - JPMBB.

\section{Acknowledgements}

We are grateful to the Chairs and staff of the Neonatal Medicine Department who facilitated access to the participants in this study. We extend our special thanks to all the families who agreed to take part in this research project. 


\section{Kangaroo supported diagonal flexion positioning: positive impact on maternal stress and postpartum depression risk and on skin-to-skin practice with very preterm infants.}

\section{Abstract}

Purpose. To test the effects of a new skin-to-skin Supported Diagonal Flexion (SDF) positioning on maternal stress, postpartum depression risk and skin-to-skin daily practice, in comparison with the usual Kangaroo Care in Upright positioning, during the first weeks after very premature birth.

Design. Thirty-four mothers and their very preterm infants were assigned to one of the two Kangaroo Care positioning, either the Upright $(n=17)$ or the SDF positioning $(n=17)$. Maternal risk for depression and stress feelings were assessed through questionnaires before the first kangaroo care, 15 days later and at 40 weeks and 3 months corrected age. Data on daily kangaroo care practice was collected during 15 consecutive days starting from the very first skin-to-skin session.

Results. The depression risk score was significantly lower in SDF positioning mothers after 15 days of skin-to-skin practice and at 40 weeks and 3 months corrected age. In the SDF group, mothers chose to practice Kangaroo Care during a significantly longer period of time per session.

Conclusion. Our results support the hypothesis of a positive impact of SDF Kangaroo positioning on maternal postpartum risk of depression and skin-to-skin practice.

\section{Keywords}

Kangaroo mother care; Skin-to-skin; Premature birth; Postpartum depression; Postpartum stress; Supported Diagonal Flexion positioning; Very preterm infant; NICU.

\section{Abbreviations}

PPD: Postpartum depression

PT: Preterm

ELBW: Early Low Birth Weight

NICU: Neonatal intensive care unit

SSC: Skin-to-skin contact

KC: Kangaroo Care

SDF positioning: Supported diagonal flexion positioning

EPDS: Edinburgh postpartum depression scale

PSS: Parental stressor scale

PPQ: Perinatal post-traumatic stress disorder questionnaire 
Premature birth is associated with high stress and anxiety levels in parents (Segre et al., 2014; Spinelli et al., 2013; Forcada-Guex, 2011, Davis, 2003), including post-traumatic stress (Anderson and Cacola, 2017, Holditch-Davis et al., 2015). In their meta-analysis, Wisner et al. (2013) pointed out that $40 \%$ of mothers with a preterm (PT) baby presented postpartum depressive (PPD) symptoms. Moreover, Bergström et al. (2012) observed that women who were not offered counselling during their infant's stay in the NICU had a $60 \%$ increase in the risk for PPD onset. Several studies found that early parental stress could influence the interrelationship between preterm birth and PPD (Carson et al., 2015; Gray et al., 2013; Lefkowitz et al., 2010).

Several factors causing major parental stress have been reported in the literature. Some authors pointed out that very low birth weight, associated to prematurity and its heightened medical risks, can greatly increase parental stress, specifically in relation with the survival and health of the PT baby (Kawafha, 2018; Singer et al., 2003). Dudek-Shriber (2004) highlighted that younger, married and more educated mothers report higher levels of stress, whereas Carter et al. (2007) reported that singlehood, low income and low educational attainment negatively impact parental stress, regardless of the newborn's gestational age. Authors also noted that for mothers, high stress is associated with lower income, living with a partner and an abnormal pregnancy scan. Other predictors of stress include length of stay, extreme prematurity and cardiovascular diagnosis (Dudek-Shriber, 2004). Parents describe preterm birth, but also hospitalization and aftermath, as traumatic events (Kantrowitz-Gordon et al., 2016), in particular when they have no previous NICU experience (Carter et al., 2007). Baía et al. (2016) found that mothers rate the overall hospitalization experience as more stressful than the median for every subscales of the Parental Stressor Scale, with the 'Parental role alteration' subscale rated as the most stressful. Moreover, higher maternal anxiety during the neonatal intensive care unit (NICU) stay is associated with less efficient parenting from birth to preschool age (Zelkowitz and Papageorgiou, 2005). Neri (2015) observed higher prevalence of depressive and anxious symptoms in early low birth weight (ELBW)'s mothers and according to Silverstein et al. (2010), depressed mothers of ELBW infants, aged 11 months to 4 years, had a negative perception of their infant's behavior, in particular regarding their social abilities.

The literature focusing on interactions between parents and their PT has reported a negative impact of maternal stress (Neri, 2015; Muller- Nix et al., 2004) and PPD (Korja et al., 2008) on the quality of early interactions. Muller-Nix et al. (2004) found that prematurity reduces mothers' responsiveness, as they appear less sensitive and more intrusive with their infants at a corrected age of 6 months. This result adds to Lester et al. (1995)'s results showing less touching, vocalizing and gazing of mothers with PT infants. Forcada-Guex et al. (2011) suggested that this impact on parental behaviors could be due to post-traumatic stress disorder, which creates a permanent latent preoccupation about infant health and affects parents' ability to embrace their role and build adapted early affective relationships. To break this deleterious loop in a highly medicalized environment, some authors pointed out the necessity to adopt a more human approach by favoring more parent-PT infant contact from the very beginning (Roué et al., 2017). SSC contact (SSC) is currently the only relational multisensory care method offered to a mother and her infant immediately after birth in NICUs. SSC is widely practiced by positioning the baby between the mother's breasts, in an upright position, chest to chest (WHO, 2003).

The SSC situation is suitable for consistent and reciprocal interaction. Based on the Kangaroo Care (KC) program included in the Newborn Individualized Development Care Assessment Program, such relational care has numerous well-known positive effects on the development of PT infants (Athanasopoulou and Fox, 2014). These benefits include an improvement of cognitive 
development, a reduction of the frequency of infections as well as positive results on sleeping, crying, thermal regulation, weight gain, heart and respiratory rate, energy expenditure and oxygenation (Dodd, 2005, Hall \& Kirsten, 2008, Ludington-Hoe, 2011). In addition, positive results on mother-infant interaction, maternal mood and sense of adaptation have been evidenced for infants and their families (Herizchi et al, 2017; Cho et al, 2016; Charpak et al.; 2005; Tallandini et al.,2006; Scalembra, 2006; Tessier et al., 2011).

In their recent meta-analysis, Athanasopoulou and Fox (2014) pointed out controversial results concerning the effect of $\mathrm{KC}$ on maternal mood. Indeed, some studies showed an improvement of maternal mood in mothers who practiced KC vs. mothers who did not (De Macedo et al, 2007; Feldman et al., 2002; Tallandini and Scalembra, 2006; Tessier et al., 1998), whereas others did not (Ahn et al, 2010; Miles et al., 2006; Roberts et al., 2000; Whitelaw et al, 1988). Tessier et al. (1998) reported that mothers who practiced $\mathrm{KC}$ felt more competent during care with their PT infant and were less affected by separation. Athanasopoulou and Fox (2014) explained that these divergent results could be due to methodological limitations, such as the way $\mathrm{KC}$ was practiced. Indeed, $\mathrm{KC}$ is likely to vary substantially in different NICUs, in particular when comparing continuous and intermittent $\mathrm{KC}$.

Buil et al. (2016) investigated the impact of positioning during SSC sessions on mother and infant well-being and on mother-infant communication. They conducted an observational, prospective, single-center study using an innovative kangaroo 'supported diagonal flexion' (SDF) positioning. This positioning was developed in their NICU according to recent recommendations promoting a 'semi reclined positioning' (Ludington-Hoe et al., 2008; Nyqvist et al., 2010). The results support the idea that the kangaroo SDF positioning technique is physiologically safe and has obvious immediate benefits on mothers' infant-directed communicative behaviors (Buil et al., 2016). Moreover, authors observed a significant decrease of the risk of postnatal depression with the new SDF positioning in comparison with the usual positioning practiced in the NICU where the study was conducted. However, Buil et al. (2016)'s study was solely observational and had some limitations in its design.

This monocentric longitudinal matched-pair case-control study aimed to test the effect of a new SSC SDF positioning on maternal stress and PPD risk in comparison with $\mathrm{KC}$ in Upright positioning. A secondary aim was to determine if and how SDF positioning influenced the way SSC was practiced by mothers every day during the first weeks after very premature birth.

\section{Methods}

\section{Participants}

The study was conducted from May 2015 to June 2016, in a level III NICU at the Centre Hospitalier Intercommunal de Créteil (France). Among the 59 very preterm births $(27<32$ weeks' gestation) which occurred during the inclusion period, 53 met inclusion criteria (no secondary neurological and or severe medical conditions linked to premature birth, i.e., no neurological defects due to several vascular hemorrhage (IVH grade III or IV), no incapacitating physical or psychological disease in the mother). Seven mothers refused to participate, and two inclusions were missed. Among the remaining 44 births, two were lost during follow-up and eight were multiple births which were not included in the present report. The final sample thus included 34 very preterm and their mothers. 


\section{Procedure}

\section{Case-control matching}

The first 17 dyads were proposed the KC positioning usually practiced in the NICU were the study was conducted, i.e. chest to chest between the mother's breasts, in an upright position, with a breastfeeding nursing pillow (see figure 1a). Nurses of the NICU trained to the practice of the new SDF positioning during a month. This new KC SDF positioning was proposed to 17 dyads ('case' dyads) matched to the first 17 dyads on newborns' gestational age and weight ('control' dyads). The same team of nurses proposed Upright and SDF positioning. The two KC positionings represented the same daily workload.

\section{Insert Figure 1 about here}

In KC SDF positioning, the baby is off-center and semi-reclined on the mother's chest, chest-tochest (Buil et al., 2016). The position is characterized by a slightly flexed body axis, with the limbs retracted in a preventive posture and the head in line with the body axis to prevent side-to-side toppling and to free respiratory permeability (Nyqvist et al., 2010), moderately externally rotated hips in flexion-abduction (Vaivre-Douret et al., 2004), with adducted shoulders (Ferrari et al., 2007). The baby's head turns toward the mother's face and is located between the nipple and the clavicle. His/her arms and legs are flexed, in a naturally adopted asymmetrical tonic neck posture (Casaer, 1979), according to the baby's term and comfort. The baby is naked and positioned inside the mother's clothes, a baby wrap adjusted around the two is used to support and help maintain the baby's posture and to relieve the mother. The chosen tool is a knitted baby wrap, with a special density of $\pm 300 \mathrm{gr} / \mathrm{m} 2$, made of $95 \%$ cotton and $5 \%$ elastane, allowing 2 way stretching. The baby wrap is placed over the mother's clothes with an asymmetric diagonal special knot that allows precise adjustment to both morphologies, while maintaining the baby in the desired posture (see Figure 1b). In both positions, the mother is comfortably seated in an adjustable armchair, her back inclined $40^{\circ}$, with a toe-clip, dim light and a quiet atmosphere.

Risk of depression and stress measurement

Participating mothers filled in the following questionnaires when they were alone and handed them back to the researcher $(\mathrm{AB})$ in a sealed envelope.

Risk for PPD was assessed using the Edinburgh Postpartum Depression Scale (EPDS). EPDS is a 10-item self-rating scale designed to screen a broad population for perinatal depression risk (Cox et al., 1987). This scale covers the symptomatology commonly associated with depression, excluding somatic dimensions such as fatigue and appetite variations, which are often found during the anteand postnatal periods. Each item is scored on a 4-point scale (0 to 3), with a total score ranging from 0 to 30. It can be completed and scored quickly and has a high level of acceptability. The French validated version was used (Guedeney et al., 1995). Mothers were invited to fill the EPDS four times: before the first SSC session, 15 days later (before the SSC session), at 40 weeks of corrected age, and at 3 months of corrected age.

Parental stress was assessed using the Parental Stressor Scale: Neonatal Intensive Care Unit (PSS:NICU) (Miles et al., 1993). The PSS:NICU is a 26-item self-rating questionnaire designed to measure parental perception of stressors arising from the physical and psychosocial environment of the NICU. It includes three scales: Parental role alterations, Sight and sounds of the Unit, and Infant behavior and appearance. The parent answers each item either by using 'na' if not applicable, or on a five-point Likert scale, ranging from 'no stress' to 'extreme stress'. We used the French validated 
version (Faure et al., 2008). As the PSS requires that mothers have had prolonged contact with their baby, we used it 15 days after the first SSC session (before the SSC session).

The Perinatal Post-traumatic stress disorder Questionnaire (PPQ) (Quinnell and Hynan, 1999) is a 14-item self-rating questionnaire based on Diagnostic and Statistical Manual of Mental Disorders ( $4^{\text {th }}$ edition) criterion, which assesses the presence of maternal post-traumatic stress symptoms during the past month. Items relate to their experience of their infant's birth and the perinatal period in general. We used the French validated version (Pierrehumbert et al., 2004). The PPQ is designed to be used at least 1 month after the traumatic event; we therefore offered it to mothers at 40 weeks of corrected age and at 3 months of corrected age.

\section{SSC data collection}

Data on KC practice were collected during 15 consecutive days, from the first SSC session onwards. As in most high-tech NICU settings, our study's NICU proposes intermittent KC, once to several times a day and for a variable number of days (Nyqvist et al., 2010). The nurses of our study's NICU had been involved in development care for many years. They routinely offer parents to practice SCC rapidly after birth. They are in charge of a maximum of 3 PT infants at a time. Hence, mothers said they felt free to practice SSC and to end the sessions whenever they wanted, according to their baby's health and to the nursing daily care organization. Nurses recorded every session practiced by the 34 mothers during 15 days, as well as their respective durations. All the information was reported and thus accessible in the medical file. Socio-demographic, Ob/Gyn, delivery and birth data were also obtained from medical files.

\section{Statistical analysis}

The analyses were performed using Stata for Windows (version 14; StataCorp). Conditional logistic regression was conducted with maternal age, parity, gestational age, birthweight, length of stay in NICU and length of stay in the Division of Neonatal Pediatrics as potential confounders.

\section{Ethical considerations}

All mothers were offered to participate to the research study on a voluntary basis, within the first two days postpartum, and in all cases before the first SSC session. Every mother whose baby met the inclusion criteria was informed of the research by a letter in the NICU. Mothers gave a written informed consent before participating. An initial information-based meeting was organized prior to data collection. This research was approved by the French Local Ethics Consulting Committee for the Protection of Persons (IRB n 2015120001072).

\section{Results}

Table 1 shows sociodemographic characteristics, ObGyn and delivery data associated to the two groups. No significant difference was found between the two groups of mothers.

\section{Insert Table 1 about here}

Regarding birth data, PT babies seemed more at risk in the SDF group, with more births before 28 weeks GA, more newborns under 1000 g., and fewer newborns breathing spontaneously. However, there was no significant difference between the two groups of babies (see Table 2).

Insert Table 2 about here 


\section{Maternal stress and depression risk}

The first measures of the risk of depression (before the first SSC session), were quite comparable for the SDF positioning group and the usual positioning group, with EPDS scores of 13.8 and 12.9 respectively (see Table 3). After 15 days of $\mathrm{KC}$ practice, both scores fell under 10, a decrease that appeared significantly higher in the SDF group positioning after adjustment. Furthermore, the EPDS score remained significantly lower at 40 weeks and 3 months of corrected age in the SDF positioning group, compared to the Upright positioning one.

Insert Table 3 about here

Regarding PSS:NICU scores after 15 days of $\mathrm{KC}$ practice, all but the parental role alteration scores were lower in the SDF positioning group. However, these differences did not reach significance. This was also the case for the maternal PPQ score at 40 weeks and 3 months of corrected age, which seemed lower in SDF mothers, but the difference was not significant.

\section{Maternal KC practice}

Table 4 presents data collected on $\mathrm{KC}$ practice during the first 15 days of practice. It shows that mothers practiced $\mathrm{KC}$ on average four times a week, with no difference between groups. Regarding the mean duration of SSC sessions, Figure 2 shows that nine mothers, out of the 17 in the SDF positioning group, chose to stay on average longer in SSC than any mother did in the Upright positioning group. Indeed, we observed significant differences in the mean and maximum durations (before and after adjustment; see Table 4).

Insert Figure 2 about here

Insert Table 4 about here

\section{Discussion}

In the present study, our first aim was to test the effect of the new KC SDF positioning on maternal stress and PPD, in comparison with the $\mathrm{KC}$ in Upright positioning. Our results confirmed the hypothesis of a positive impact on maternal mood, assessed through EPDS, but not on stress, assessed through PSS:NICU and PPQ. Converging with most studies on the relation between KC practice and maternal mood (Athanasopoulou and Fox, 2014), we observed a decrease in the risk of depression in both groups, at the second and third assessments. However, SDF positioning was associated with a greater decrease15 days after the first SSC session, confirming Buil et al. (2016)'s observations, but also at 40 weeks and 3 months of corrected age, whereas the score tended to stagnate at 40 weeks of corrected age in the Upright positioning group.

At birth, the risk of depression was quite similar in mothers of both groups, even though slightly higher in the SDF group, which could be explained by sensitively more at risk pregnancies and more vulnerable newborns in this group. Besides, the significant decreases, respectively after 15 days of KC practice and at 40 weeks and 3 months of corrected age, were obtained after adjustment on mother and infant characteristics. This decrease in the risk of depression supports the idea that SDF positioning has positive short- and long-term effects on mothers, who appeared to feel less overwhelmed or vulnerable at the time of assessment (Cox et al., 2014).

Our second aim was to determine if and how SDF positioning impacted the way SSC is practiced by mothers during the first weeks after very premature birth. Our results evidence that in the SDF group, mothers chose to practice longer KC sessions. Keeping in mind that mothers freely initiated 
and ended intermittent $\mathrm{KC}$ (when non-medical contraindication), this result strongly supports the idea that mothers in the SDF positioning group felt more comfortable to prolong this moment. Indeed, the innovative SDF positioning offers an opportunity for both mother and infant to discover each other and communicate in synchrony (Feldman and Eidelman, 2007). This might relate to what SDF positioning offers: eyes-to-eyes contact, postural and tonic adjustment of the preterm, as well as the envelope brought by the baby wrap.

Neu and Robinson (2010) compared KC with traditional holding (with a blanket) and found better mother-baby interaction in the $\mathrm{KC}$ group. The added value of $\mathrm{KC}$ could be attributed to close physical contact and maximized touch. Our results are in line with this work and go further, for they support the hypothesis that SSC behaviors are more complex than a mere increase in shared feelings. Indeed, by changing the way mother and baby are together in close contact during the care, the quality of mutual communication appears more varied, rich and adjusted (Buil et al., 2017a; Buil et al., 2017b; Devouche, 2017). This dedicated moment positively acts upon each partner's well-being, which in turn positively influences the quality of the relationship, thus creating a virtuous loop. From this point of view, rather than the amount of close contact, it might be the quality of the experience that matters most, in terms of behavioral and affective interactions (Stern, 1995) and tonic-emotional dialogue (De Ajuriaguerra, 1983).

\section{Conclusion}

The Kangaroo supported diagonal flexion positioning has a positive impact on maternal stress, postpartum depression risk and skin-to-skin practice with very preterm infants. Much more than a cuddly moment, SCC is an opportunity to empower mothers: to help them feel competent by interacting with their baby and by experimenting positive responsiveness. The kangaroo SDF positioning makes this primary encounter more successful by offering more eyes-to-eyes contact and better postural and tonic adjustment. Although a larger study cohort would have improved the robustness of our evidence, our results provide the first valuable evidence of the benefits associated with kangaroo SDF positioning and plead for the necessity to reconsider the kangaroo positioning technique guidelines specifically in high technology NICUs.

\section{Limitations}

In our study, previous history of depression was unknown. Some information was available in the medical file but it was fragmentary and thus not reliable. Moreover, we excluded mothers with previous psychiatrics treatments. We focused our analysis on $\mathrm{KC}$ practice during a 15-day period to reduce the risk of missing data. Indeed, day-to-day $\mathrm{KC}$ follow-up during a longer period, and all the more until 40 weeks of corrected age, would have been difficult in terms of feasibility, as some mothers were back at home, and others had stopped SSC. The 15-day period provided a relevant reflection of the frequency and duration of maternal spontaneous natural $\mathrm{KC}$ practices.

\section{Conflict of interest}

The authors declare that they have no competing interest.

\section{Ethics}

This research was approved by the French Local Ethics Consulting Committee for the Protection of Persons (IRB n 2015120001072). 


\section{References}

Ahn, H.Y., Lee, J., \& Shin, H.J. (2010). Kangaroo care on premature infant growth and maternal attachment and post-partum depression in South Korea. Journal of Tropical Pediatrics, 56, 342344. doi:10.1093/tropej/fmq063

Alkozei, A., McMahon, E., \& Lahav, A. (2014). Stress levels and depressive symptoms in NICU mothers in the early postpartum period. The Journal of Maternal-Fetal \& Neonatal Medicine, 27(17), 1738-1743.

Anderson, C., \& Cacola, P. (2017). Implications of preterm birth for maternal mental health and infant development. MCN: The American Journal of Maternal/Child Nursing, 42(2), 108-114.

Athanasopoulou, E., \& Fox, J. R. (2014). Effects of kangaroo mother care on maternal mood and interaction patterns between parents and their preterm, low birth weight infants: a systematic review. Infant mental health journal, 35(3), 245-262.

Baía, I., Amorim, M., Silva, S., Kelly-Irving, M., de Freitas, C., \& Alves, E. (2016). Parenting very preterm infants and stress in Neonatal Intensive Care Units. Early human development, 101, 3-9.

Bergström, E. B., Wallin, L., Thomson, G., \& Flacking, R. (2012). Postpartum depression in mothers of infants cared for in a Neonatal Intensive Care Unit-Incidence and associated factors. Journal of Neonatal Nursing, 18(4), 143-151.

Buil A., Renault N, Boulonnois E, Apter G, Devouche E. (2017) Une installation innovante lors du peau à peau en néonatologie. Soins Pédiatrie Puériculture, 299, 36-40. http://dx.doi.org/10.1016/j.spp.2017.09.008

Buil, A., Fillon-Devys, D., Granger, A., Roger, K., Thomas, N., Apter, G. \& Devouche, E. (2017). Impact de l'installation en Flexion diagonale soutenue sur le maternage tactile spontané lors de la première séance de peau-à-peau en réanimation néonatale. Neuropsychiatrie de l'Enfance et de l'Adolescence. http://dx.doi.org/10.1016/j.neurenf.2017.05.003.

Buil, A., Carchon, I., Apter, G., Laborne, F.X., Granier, M. \& Devouche, E. (2016). Kangaroo supported diagonal flexion positioning: New insights into SSC contact for communication between mothers and very preterm infants. Archives de Pédiatrie, 23(9),913-20.

Casaer, P. (1979). Postural behaviour in newborn infants (Vol. 72). Spastics International Medical Publications.

Carson, C., Redshaw, M., Gray, R., \& Quigley, M. A. (2015). Risk of psychological distress in parents of preterm children in the first year: evidence from the UK Millennium Cohort Study. BMJ open, 5(12), e007942.

Carter, J. D., Mulder, R. T., \& Darlow, B. A. (2007). Parental stress in the NICU: The influence of personality, psychological, pregnancy and family factors. Personality and Mental Health, 1(1), 40-50.

Charpak, N., Ruiz-Pel'aez, J.G., Zupan, J., Cattaneo, A., Figueroa, Z., Tessier, R. et al.. (2005). Kangaroo mother care: 25 years after. Acta Paediatrica, 94, 514-522.

Cho, E. S., Kim, S. J., Kwon, M. S., Cho, H., Kim, E. H., Jun, E. M., \& Lee, S. (2016). The effects of kangaroo care in the neonatal intensive care unit on the physiological functions of preterm 
infants, maternal-infant attachment, and maternal stress. Journal of Pediatric Nursing: Nursing Care of Children and Families, 31(4), 430-438.

Cox, J., Holden, J., \& Henshaw, C. (2014). Perinatal Mental Health: The Edinburgh Postnatal Depression Scale (EPDS) Manual (2nd edn). RCPsych Publications.

Cox, J. L., Holden, J. M., \& Sagovsky, R. (1987). Detection of postnatal depression: development of the 10-item Edinburgh Postnatal Depression Scale. The British journal of psychiatry, 150(6), 782-786.

Davis, L., Edwards, H., Mohay, H., \& Wollin, J. (2003). The impact of very premature birth on the psychological health of mothers. Early human development, 73(1-2), 61-70.

Dodd, V.L. (2005). Implications of kangaroo mother care for growth and development in preterm infants. Journal of Obstetric, Gynecologic, \& Neonatal Nursing, 34, 218-232.

De Ajuriaguerra, J. (1983). De los movimientos espontáneos al diálogo tónico-postural ya las actividades expresivas. Anuario de psicología/The UB Journal of psychology, (28), 7-18.

De Macedo, E.C., Cruvinel, F., Lukasova, K., \& D'Antino, M.E. (2007). The mood variation in mothers of preterm infants in kangaroo mother care and conventional incubator care. Journal of Tropical Pediatrics, 53, 344-346.

Dudek-Shriber, L. (2004). Parent stress in the neonatal intensive care unit and the influence of parent and infant characteristics. American Journal of Occupational Therapy, 58(5), 509-520.

Faure, N., Borghini., A., Pierrehumbert, B.,Tolsa, J., F.,Muller-Nix, C., Morisod Harari, M.) PSS francais

Feldman, R., \& Eidelman, A. I. (2007). Maternal postpartum behavior and the emergence of infantmother and infant-father synchrony in preterm and full-term infants: The role of neonatal vagal tone. Developmental psychobiology, 49(3), 290-302.

Feldman, R., Eidelman, A.I., Sirota, L., \& Weller, A. (2002).Comparison of SSC (kangaroo) and traditional care: Parenting outcomes and preterm infant development. Paediatrics, 110, 16-26.

Ferrari, F., Bertoncelli, N., Gallo, C., Roversi, M. F., Guerra, M. P., Ranzi, A., \& Hadders-Algra, M. (2007). Posture and movement in healthy preterm infants in supine position in and outside the nest. Archives of Disease in Childhood-Fetal and Neonatal Edition, 92(5), F386-F390.

Forcada-Guex, M., Borghini, A., Pierrehumbert, B., Ansermet, F., \& Muller-Nix, C. (2011). Prematurity, maternal posttraumatic stress and consequences on the mother-infant relationship. Early human development, 87(1), 21-26.

Forcada-Guex, M., Pierrehumbert, B., Borghini, A., Moessinger, A., \& Muller-Nix, C. (2006). Early dyadic patterns of mother-infant interactions and outcomes of prematurity at 18 months. Pediatrics, 118(1), e107-e114.

Gray, P. H., Edwards, D. M., O'Callaghan, M. J., Cuskelly, M., \& Gibbons, K. (2013). Parenting stress in mothers of very preterm infants - influence of development, temperament and maternal depression. Hurly Hun Development, 825-629. https://doi.org/10.1016/j.earlhumdev.2013.04.005 
Guedeney, N., Fermanian, J., Guelfi, J. D., \& Delour, M. (1995). Premiers résultats de la traduction de l'edinburgh post-natal depression scale sur une population parisienne. Devenir, 7(2), 69-92.

Hall, D., \& Kirsten, G. (2008). Kangaroo mother care-A review. Transfusion Medicine, 18, 7782.

Herizchi, S., Hosseini, M. B., \& Ghoreishizadeh, M. (2017). The Impact of Kangaroo-Mother Care on Postpartum Depression in Mothers of Premature Infants. INTERNATIONAL JOURNAL OF WOMENS HEALTH AND REPRODUCTION SCIENCES, 5(4), 312-317.

Holditch-Davis, D., Santos, H., Levy, J., White-Traut, R., O'Shea, T. M., Geraldo, V., \& David, R. (2015). Patterns of psychological distress in mothers of preterm infants. Infant Behavior and Development, 41, 154-163.

Kantrowitz-Gordon, I., Altman, M. R., \& Vandermause, R. (2016). Prolonged distress of parents after early preterm birth. Journal of Obstetric, Gynecologic \& Neonatal Nursing, 45(2), 196-209.

Kawafha, M. M. (2018). Parental stress in the neonate intensive care unit and its association with parental and infant characteristics. Journal of Neonatal Nursing.

Korja, R., Savonlahti, E., Ahlqvist $\square$ Björkroth, S., Stolt, S., Haataja, L., Lapinleimu, H., ... \& PIPARI Study Group. (2008). Maternal depression is associated with mother-infant interaction in preterm infants. Acta Paediatrica, 97(6), 724-730.

Lefkowitz, D. S., Baxt, C., \& Evans, J. R. (2010). Prevalence and correlates of posttraumatic stress and postpartum depression in parents of infants in the Neonatal Intensive Care Unit (NICU). Journal of clinical psychology in medical settings, 17(3), 230-237.

Lester, B. M., Boukydis, C. Z., Garcia-Coll, C. T., Peucker, M., McGrath, M. M., Vohr, B. R., ... \& Oh, W. (1995). Developmental outcome as a function of the goodness of fit between the infant's cry characteristics and the mother's perception of her infant's cry. Pediatrics, 95(4), 516-521.

Ludington-Hoe, M.S. (2011). Evidence-based review of physiologic effects of kangaroo care. Current Women's Health Reviews,7(3),243- 253.

Ludington-Hoe, S. M., Morgan, K., \& Abouelfettoh, A. (2008). A clinical guideline for implementation of kangaroo care with premature infants of 30 or more weeks' postmenstrual age. Advances in Neonatal Care, 8(3), S3-S23.

Lyons, S. (1998). A prospective study of post traumatic stress symptoms 1 month following childbirth in a group of 42 first-time mothers. Journal of Reproductive and Infant Psychology, 16(2-3), 91-105.

Miles, M.S., Funk, S.G., \& Carlson, J. (1993). Parental stressor scale: neonatal intensive care unit. Nursing Research, 42, 148-152.

Miles, R., Cowan, F., Glover, V., Stevenson, J., \& Modi, N. (2006). A controlled trial of SSC contact in extremely preterm infants. Early Human Development, 82, 447-455.

Muller-Nix C, Forcada-Guex M, Pierrehumbert B, Jaunin L, Borghini A, Ansermet F. Prematurity, maternal stress and mother-child interactions. Early Hum Dev 2004; 79: 145-58. 
Neri, E., Agostini, F., Salvatori, P., Biasini, A., \& Monti, F. (2015). Mother-preterm infant interactions at 3 months of corrected age: influence of maternal depression, anxiety and neonatal birth weight. Frontiers in psychology, 6. doi:10.3389/fpsyg.2015.01234

Neu, M., \& Robinson, J. (2010). Maternal holding of preterm infants during the early weeks after birth and dyad interaction at six months. Journal of Obstetric, Gynecologic, \& Neonatal Nursing, 39(4), 401-414.

Nyqvist, K. H., Anderson, G. C., Bergman, N., Cattaneo, A., Charpak, N., Davanzo, R., ... \& Pallás $\square$ Allonso, C. (2010). Towards universal kangaroo mother care: recommendations and report from the first European conference and seventh international workshop on kangaroo mother care. Acta Paediatrica, 99(6), 820-826.

Pierrehumbert, B., Borghini, A., Forcada-Guex, M., Jaunin, L., Müller-Nix, C., \& Ansermet, F. (2004, November). Validation française d'un questionnaire de stress post-traumatique destiné aux parents d'enfants présentant un risque périnatal élevé. In Annales Médico-psychologiques, revue psychiatrique (Vol. 162, No. 9, pp. 711-721). Elsevier Masson.

Roberts, K.L., Paynter, C., \& McEwan, B. (2000). A comparison of kangaroo mother care and conventional cuddling care. Neonatal Work, 19, 31-35.

Roué, J. M., Kuhn, P., Maestro, M. L., Maastrup, R. A., Mitanchez, D., Westrup, B., \& Sizun, J. (2017). Eight principles for patient-centred and family-centred care for newborns in the neonatal intensive care unit. Archives of Disease in Childhood-Fetal and Neonatal Edition, fetalneonatal2016.

Santos, H., Yang, Q., Docherty, S. L., White $\square$ Traut, R., \& Holditch $\square$ Davis, D. (2016). Relationship of Maternal Psychological Distress Classes to Later Mother-Infant Interaction, Home Environment, and Infant Development in Preterm Infants. Research in nursing \& health, 39(3), 175-186. doi:10.1002/nur.21719

Segre, L. S., McCabe, J. E., Chuffo-Siewert, R., \& O'Hara, M. W. (2014). Depression and anxiety symptoms in mothers of newborns hospitalized on the neonatal intensive care unit. Nursing research, 63(5), 320 .

Singer, L.T., Fulton, S., Davillier, M., Koshy, D., Salvator, A., \& Baley,J.E. (2003). Effects on infant risk status and maternal psychological distress on maternal-infant interactions during the first year of life. Journal of Developmental \& Behavioral Pediatrics, 24,233-241.

Silverstein, M., Feinberg, E., Young, R., \& Sauder, S. (2010). Maternal depression, perceptions of children's social aptitude and reported activity restriction among former very low birthweight infants. Archives of disease in childhood, archdischild181735.

Spinelli, M., Poehlmann, J., \& Bolt, D. (2013). Predictors of parenting stress trajectories in premature infant-mother dyads. Journal of Family Psychology, 27(6), 873. http://dx.doi.org/10.1037/a0034652

Stern, D. N. (1995). The motherhood constellation. Basic Books.

Tallandini, M.A., \& Scalembra, C. (2006). Kangaroo mother care and other-premature infant dyadic interaction. Infant Mental Health Journal, 27, 251-275. 
Tessier, R., Cristo, M., Nadeau, L., \& Schneider, C. (2011). Prematurity and morbidity: Could KMC reverse the process? Current Women's Health Reviews, 7(3), 254-261.

Tessier, R, Cristo, M., Velez, S., Giron, M., deCalume, Z.F., Ruiz-Palaez, J.G. et al. (1998). Kangaroo mother care and the bonding hypothesis. Pediatrics, 102, (2). doi: 10.1542/peds.102.2.e17

Turner, M., Chur-Hansen, A., Winefield, H., \& Stanners, M. (2015). The assessment of parental stress and support in the neonatal intensive care unit using the Parent Stress Scale-Neonatal Intensive Care Unit. Women and Birth, 28(3), 252-258.

Vaivre-Douret, L., Ennouri, K., Jrad, I., Garrec, C., \& Papiernik, E. (2004). Effect of positioning on the incidence of abnormalities of muscle tone in low-risk, preterm infants. European Journal of Paediatric Neurology, 8(1), 21-34.

Vigod, S. N., Villegas, L., Dennis, C. L., \& Ross, L. E. (2010). Prevalence and risk factors for postpartum depression among women with preterm and low $\square$ birth $\square$ weight infants: a systematic review. BJOG: An International Journal of Obstetrics \& Gynaecology, 117(5), 540-550.

Whitelaw, A., Heisterkamp, G., Sleath, K., Acolet, D., \& Richards, M. (1988). SSC contact for very low birth weight infants and their mothers. Archives of Disease in Childhood, 63, 1377-1381.

Zelkowitz, P., \& Papageorgiou, A. (2005). Maternal anxiety: an emerging prognostic factor in neonatology. Acta Paediatrica, 94(12), 1704-1705. 


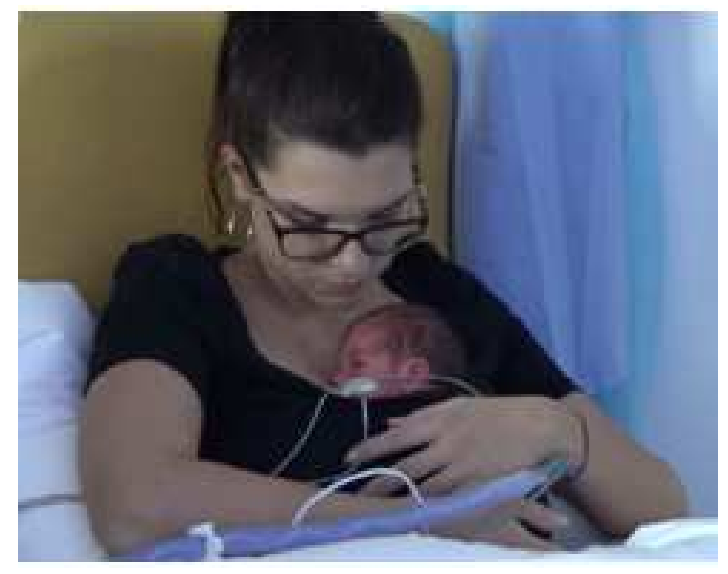

$1 \mathrm{a}$

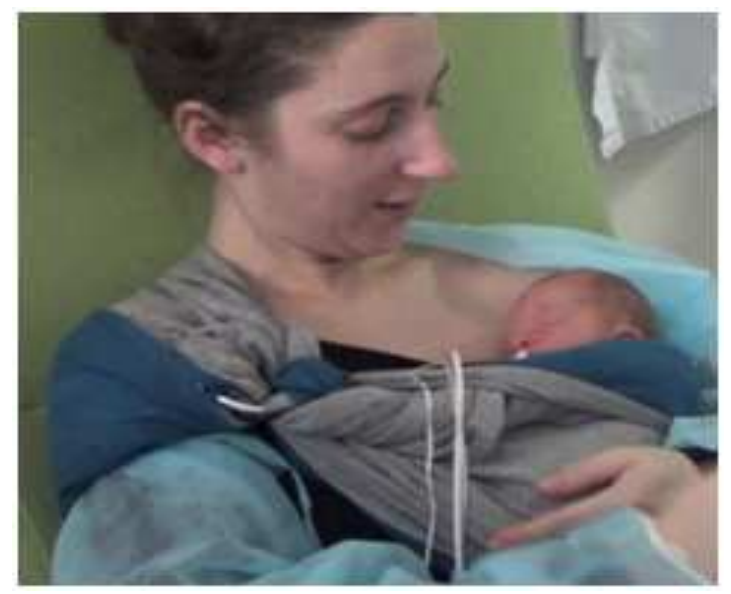

$1 \mathrm{c}$

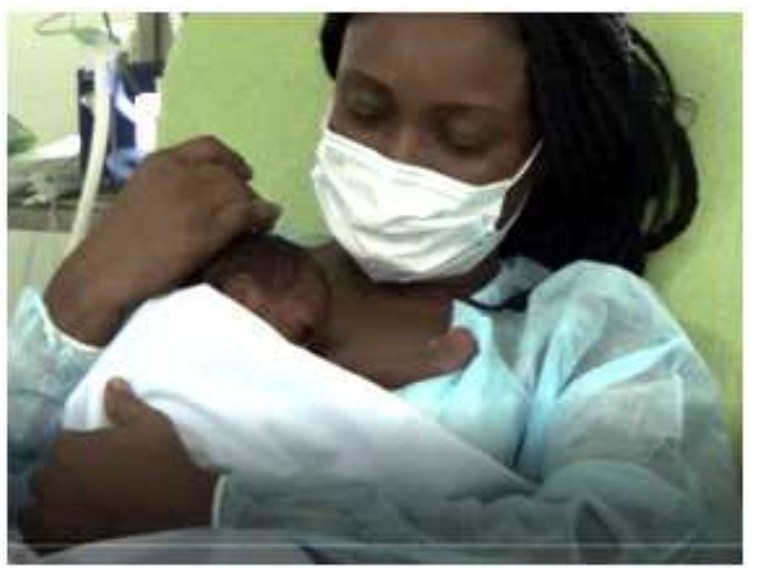

$1 \mathrm{~b}$

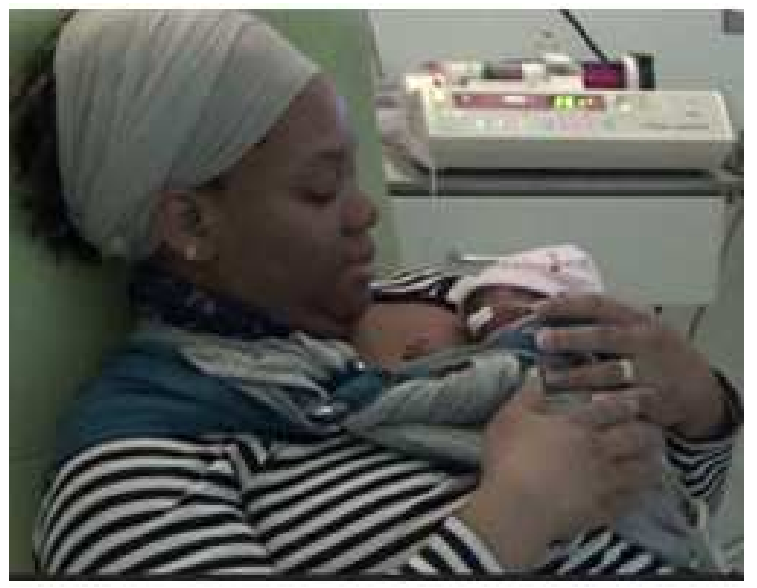

$1 \mathrm{~d}$

Figure 1. Upright positioning (1a and $1 b)$ and Supported Diagnonal Flexion (SDF) positioning (1c and $1 d$ ).

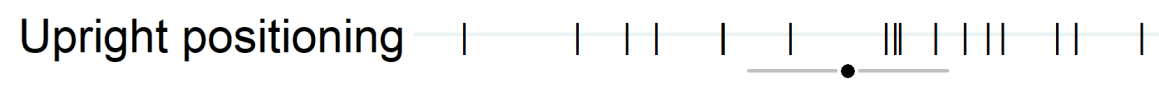

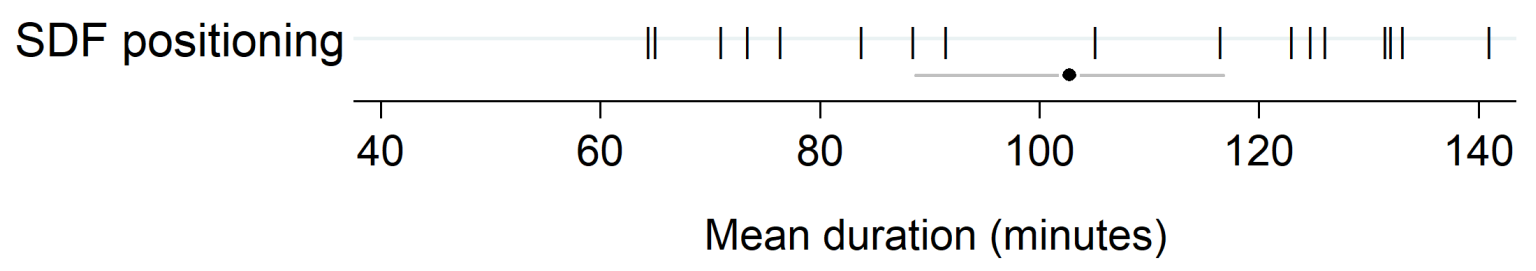

Figure 2. SSC mean duration per woman according to positioning. Each vertical dash represents a woman. Below mean duration per group and $95 \% \mathrm{Cl}$. 
Table 1. Sociodemographic, ObGyn and Delivery data according to skin to skin positioning

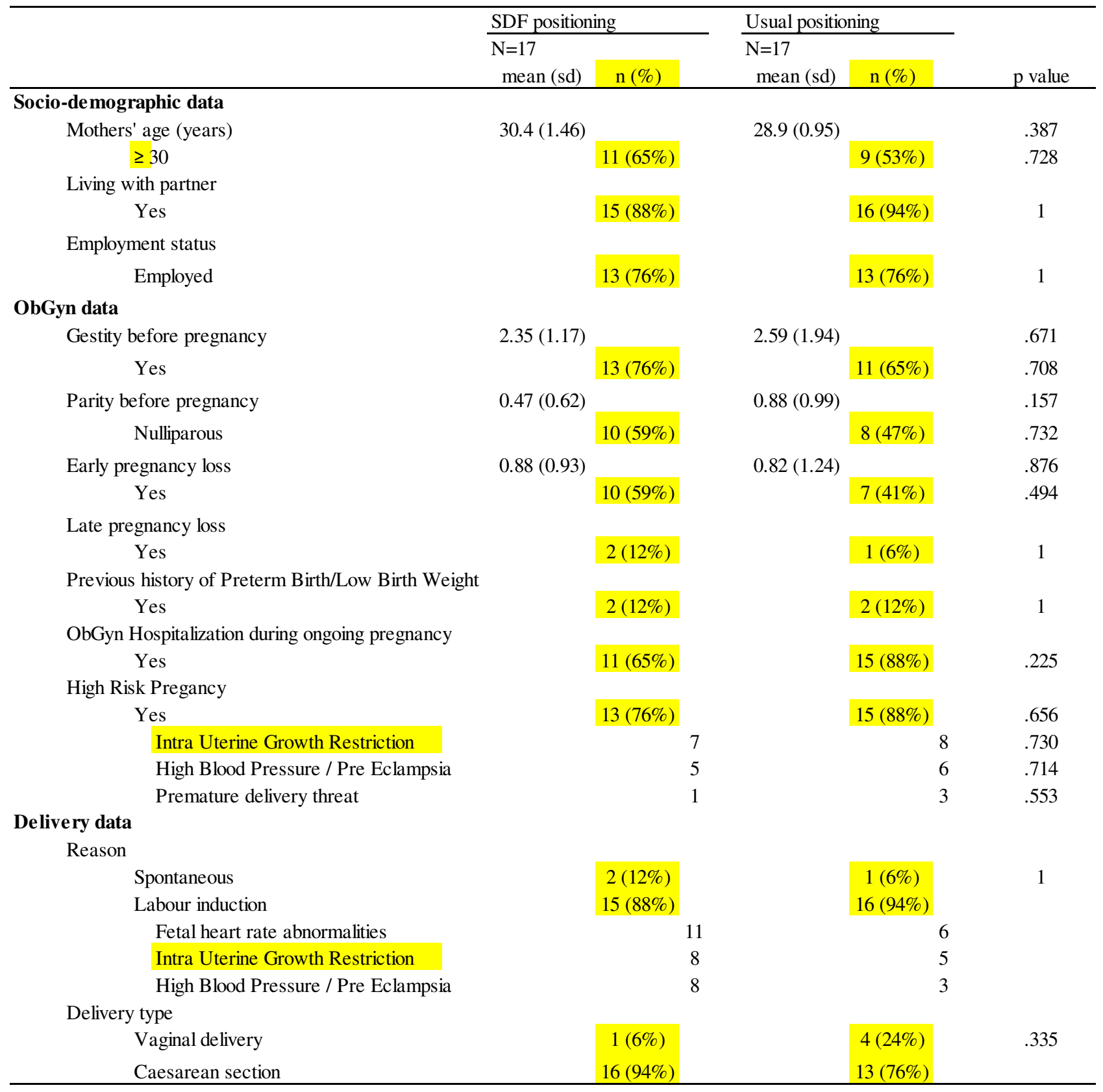


Table 2. PT infant's data at birth, at first skin to skin and 15 days later, according to skin to skin positioning.

\begin{tabular}{|c|c|c|c|c|c|}
\hline & \multicolumn{2}{|c|}{ SDF positioning } & \multicolumn{2}{|c|}{ Usual positioning } & \multirow[b]{3}{*}{$\mathrm{p}$ value } \\
\hline & $\mathrm{N}=17$ & & $\mathrm{~N}=17$ & & \\
\hline & mean $(\mathrm{sd})$ & $\mathrm{n}$ & mean $(\mathrm{sd})$ & $\mathrm{n}$ & \\
\hline \multicolumn{6}{|l|}{ Birth data } \\
\hline \multicolumn{6}{|l|}{ Gender } \\
\hline Girl & & $11(65 \%)$ & & $7(41 \%)$ & .174 \\
\hline Weight (g) & $1080(244)$ & & $1184(294)$ & & .272 \\
\hline$<1000$ & & $7(41 \%)$ & & $4(24 \%)$ & .276 \\
\hline $1000-2000$ & & $10(59 \%)$ & & $13(76 \%)$ & \\
\hline Gestational age (w) & $29.7(2.7)$ & & $30.0(1.24)$ & & .532 \\
\hline$<28$ & & $3(18 \%)$ & & $0(0 \%)$ & na \\
\hline 28 to $<32$ & & $14(82 \%)$ & & $17(100 \%)$ & \\
\hline \multicolumn{6}{|l|}{ Apgar } \\
\hline Apgar 1 & $7.1(2.7)$ & & $7.9(2.6)$ & & .409 \\
\hline Apgar 2 & $9.0(1.7)$ & & $8.7(2.2)$ & & .665 \\
\hline \multicolumn{6}{|c|}{ Spontaneous breathing } \\
\hline Yes & & $3(18 \%)$ & & $6(35 \%)$ & .251 \\
\hline \multicolumn{6}{|l|}{ Data at first skin to skin } \\
\hline Age (days) & $3.5(1,8)$ & & $3.2(2,1)$ & & .677 \\
\hline Weight (g) & $1031(208)$ & & $1115(280)$ & & .338 \\
\hline$<1000$ & & $8(47 \%)$ & & $4(24 \%)$ & .157 \\
\hline $1000-2000$ & & $9(53 \%)$ & & $13(76 \%)$ & \\
\hline \multicolumn{6}{|c|}{ Data at 15 days after first skin to skin } \\
\hline Age (days) & $18.1(2.2)$ & & $18.1(2.8)$ & & \\
\hline
\end{tabular}


Table 3. EPDS, PSS:NICU and PPQ scores according to positioning.

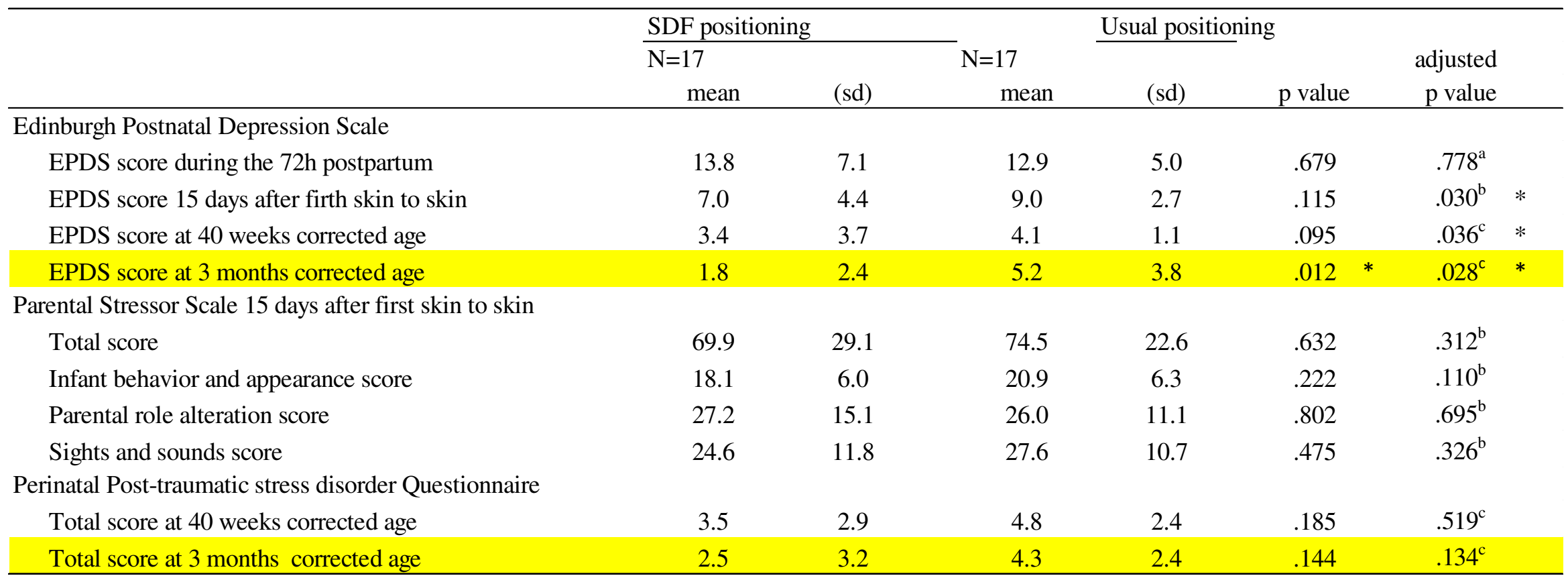

a Adjusted on maternal age, parity, gestational age and birthweight.

${ }^{\mathrm{b}}$ Adjusted on maternal age, parity, gestational age and birthweight and length of stay in NICU.

${ }^{c}$ Adjusted on maternal age, parity, length of stay in NICU and length of stay in Division of Neonatal Pediatrics.

$* p<.05$ 
Table 4. Data on SCC practice according to positioning.

\begin{tabular}{|c|c|c|c|c|c|c|c|c|}
\hline & \multicolumn{2}{|c|}{ SDF positioning } & \multicolumn{2}{|c|}{ Usual positioning } & & \\
\hline & $\mathrm{N}=17$ & & $\mathrm{~N}=17$ & & & \multicolumn{3}{|c|}{ adjusted } \\
\hline & mean & $(\mathrm{sd})$ & mean & $(\mathrm{sd})$ & $\mathrm{p}$ value & & p value ${ }^{a}$ & \\
\hline Number of skin-to-skin sessions per week & 3.8 & 1.6 & 4.3 & 1.8 & .377 & & .358 & \\
\hline Mean duration of a session (in minutes) & 103 & 27.2 & 77 & 17.5 & .003 & $* * *$ & .004 & $* * *$ \\
\hline Min duration of a session (in minutes) & 54 & 20.8 & 41 & 17.6 & .061 & & .054 & \\
\hline Max duration of a session (in minutes) & 160 & 42.0 & 122 & 37.1 & .008 & $* *$ & .016 & $*$ \\
\hline
\end{tabular}

adjusted on maternal age, parity, gestational age, birthweight and length of stay in NICU.

$* p<.05 ; * * p<.01 ; * * * p<.005$. 